\title{
RELATIONSHIP BETWEEN CRANIALAND MANDIBULAR GROWTH AND THE STAGES OF MATURATION OF THE CERVICAL VERTEBRAE
}

\author{
Melissa Feres DAMIAN ${ }^{1}$, Fernando CECHINATO ${ }^{2}$, Rafael Dagnese MOLINA ${ }^{2}$, Fábio Eduardo WOITCHUNAS ${ }^{3}$
}

\author{
1- DDS, MSc, PhD, Assistant Professor, Discipline of Radiology, Universty of Passo Fundo. \\ 2- DDS, Undergraduate student, University of Passo Fundo. \\ 3- DDS, MSc, Assistant Professor, Discipline of Orthodontic, Universty of Passo Fundo.
}

Corresponding address: Melissa Feres Damian - Universidade de Passo Fundo - Faculdade de Odontologia - Campus I - Bairro São José - BR 285 - Km 171 - 99001-970 - Caixa postal 611 - Passo Fundo/RS - e-mail: melissaodonto@upf.br - Phone: 5554 3316-8402 / Fax: 55 54 3316-8403

Received: August 23, 2006 - Modification: December 04, 2006 - Accepted: April 01, 2007

\begin{abstract}
Q uantification of the expectation of craniofacial growth during the pubertal growth spurt (PGS) is helpful in orthodontic diagnosis and treatment planning. Thus, this study investigated whether the stages of the vertebral maturation index (VMI) would be valid for estimating cranial and mandibular growth during the initial stages of PGS, testing the null hypothesis that these structures do not demonstrate differential growth dependent on the maturation stage. A study population of 45 patients of both genders with 2 lateral cephalometric radiographs, taken at a 12-month interval, was selected from files. All patients should not have been previously submitted to orthodontic treatment and should be before or during the peak stage of PGS. The S-N and Co-Gn cephalometric measurements were traced on both radiographs of each patient, by computed cephalometric tracings, for evaluation of skull and mandible, respectively. The growth of these structures was established by the difference between the measurements obtained on both tracings. The VMI stage was also estimated on the radiographs, determining the position of patients on the PGS curve at two periods, baseline and after 12 months. Cephalometric tracings and VMI estimates were performed by two calibrated examiners. Descriptive statistics revealed that both cephalometric measurements increased during the study period, especially Co-Gn, which demonstrated (ANOVA and Tukey's test; 5\% significance level), a statistically significant peak of development $(p=0.001)$, when the patient was in the VMI stage representing the PGS peak. It was concluded that the VMI stages were valid for the analysis of cranial growth and especially of mandibular growth at the initial stages of PGS, thus rejecting the null hypothesis.
\end{abstract}

Uniterms: Bone maturation; Facial growth; Cervical vertebrae.

\section{INTRODUCTION}

Prediction of the potential and magnitude of craniofacial growth is a valuable information in the diagnosis, planning and evaluation of the outcomes of orthodontic and mainly orthopedic treatment. The reason is that a better and more effective response will be obtained when the treatment is rendered during periods of faster growth, called growth spurts, especially during adolescence, in the pubertal growth spurt (PGS) ${ }^{1-4,6-21}$.

However, the PGS varies as to its onset, intensity, duration, peak and completion among individuals. Thus, chronological age is the least accurate PGS indicator ${ }^{2-4,6-9,11-}$ ${ }^{21}$. The appearance of secondary sexual characteristics, tooth mineralization and/or eruption, growth peak in height and bone development may be mentioned as the landmarks used for evaluation of PGS rather than chronological age ${ }^{8-}$
12,15,19-21. Among these, the appearance or maturation changes observed in some ossification centers have been demonstrated to be precise for the evaluation, quantification and prediction of the occurrence of PGS ${ }^{1-4,6-21}$.

For a long time, skeletal maturation has been evaluated by the ossification events on the hand and wrist on carpal radiographs (carpal maturation index - CMI), and the occurrence of these events has been positively correlated with the stage of growth acceleration of the craniofacial complex $^{7,10,13,15,17,19-21}$. However, carpal radiographs are not part of the orthodontic records conventionally requested for patient evaluation, leading to additional exposure to ionizing radiation. In order to overcome this problem, Lamparski ${ }^{12}$ (1972) suggested the interpretation of morphological changes of the cervical vertebrae to evaluate the skeletal maturation. The author justified selection of these anatomical structures because they can be observed 
on lateral cephalometric radiographs, which are routinely requested by orthodontists for the accomplishment of cephalometric tracings. Since then, the validity of the vertebral maturation index (VMI) for prediction of PGS occurrence has been investigated ${ }^{8,9,11,12}$. However, few studies so far have associated the VMI with cranial and facial growth during PGS, especially among Brazilian individuals $\mathrm{s}^{2-4,6,14,16}$

Within this context, this study evaluated whether the stages of VMI would be valid for the estimation of cranial and mandibular growth during the initial stages of PGS, investigating the null hypothesis that these structures do not present a differential growth dependent on the maturation stage of the patient.

\section{MATERIALAND METHODS}

This cross-sectional study was initiated after approval by the Institutional Review Board and was conducted on 90 lateral cephalometric radiographs obtained from files. These radiographs were taken from 45 patients submitted to orthodontic treatment at a dental school in the period from 1998 to 2004, and were used for evaluation of the maturation stages by VMI and as well as for cephalometric tracings.

The study population comprised patients of both genders, aged between 9 and 15 years, with two lateral cephalometric radiographs each taken at a 12-month interval, not previously submitted to orthodontic treatment, before or during the peak stage of PGS. Because sample selection was based on the period of PGS instead of the chronological age, there was no separation between genders. According to Arat, et al. ${ }^{1}$ (2003), the PGS of each gender occurs at different ages; however, this difference is eliminated if selection is based on skeletal maturity rather than chronological age.

Establishment of the maturation stages of cervical vertebrae was performed by the method proposed by Hassel and Farman ${ }^{9}$ (1995), which visually analyzes the cervical vertebrae $2(\mathrm{C} 2), 3(\mathrm{C} 3)$ and $4(\mathrm{C} 4)$ as to the formation of a concavity on the lower border and the body morphology, establishing six stages of skeletal maturation: 1) initiation, 2) acceleration, 3) transition, 4) deceleration, 5) maturation, and 6) completion. This analysis was visually performed by consensus between two calibrated examiners. Inter-examiner agreement was assessed by Kappa test at 5\% significance level $(\mathrm{k}=0.89)$.

Based on this evaluation, the patients were assigned to 3 groups, according to their maturation stages on both lateral cephalometric radiographs: permanence in stages before the peak, change to the subsequent stage up to the peak or permanence in the growth peak stage. Thus, patients in the initiation (1) or acceleration (2) stages on the first and second radiographs comprised Group I; patients changing from the Initiation (1) or acceleration (2) stages to the transition (3) stage comprised Group II; and patients in the transition (3) stage on both radiographs, namely during the growth peak, constituted Group III.
Thereafter, the radiographs were digitized and the Radiocef $2.0^{\circledR}$ software (Radiomemory Indústria e Comércio Ltd., Belo Horizonte, MG, Brazil) was used for accomplishing the cephalometric tracings and measurements, which allowed evaluating the cranial and mandibular growth. Digitization was performed using a scanner with transparency adapter (Umax Astra 2400SLT) at a resolution of $75 \mathrm{dpi}$ (dots per inch) and $100 \%$ size, as requested for this software. The images were stored in the hard disk in JPEG format. According to Chen, et al. ${ }^{5}$ (2004), computed cephalometric tracings are as accurate as manual tracings, with the advantage of being less time-consuming.

The S-N (distance from the sella turcica to the nasion) and Co-Gn (distance from the condyle to the gnathion) cephalometric measurements were evaluated. The S-N measurement was used for the evaluation of the anterior cranial base length, whereas the Co-Gn measurement was used for the evaluation of the total mandibular length (Figure 1). Cephalometric tracings were individually performed by the same two examiners evaluating the maturation stages of the cervical vertebrae. Thus, the value of each measurement was represented by the mean of measurements of both examiners. Kappa test was once again used at a significance level of 5\% for assessment of inter-examiner agreement $(\mathrm{k}=$ 0.94).

For each individual in Groups I, II and III, S-N and Co-Gn cephalometric measurements were assessed on both radiographs and the growth increment in this period was

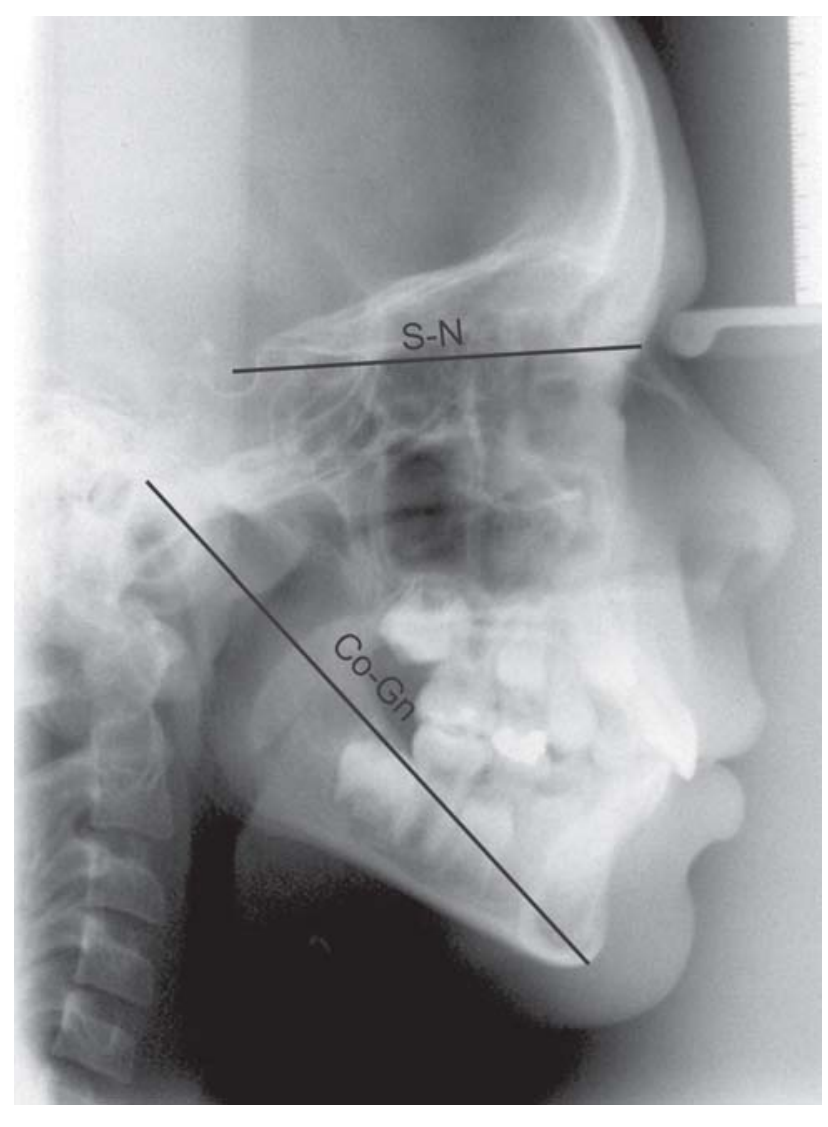

FIGURE 1- Lateral cephalometric radiograph demonstrating the cephalometric tracing of the measurements investigated 
evaluated by the difference between the second (12 months) and first (baseline) radiographs. The values of each measurement on both radiographs were assessed by descriptive statistics. Growth increments were evaluated by analysis of variance (ANOVA) and Tukey's test at 5\% significance level. Statistical tests were performed using the SPSS 10.0 for Windows (Statistical Package for Social Science Inc., Chicago, Il, USA).

\section{RESULTS}

Table 1 shows the results of descriptive statistical analysis for the values of S-N and Co-Gn measurements for the different study groups. It can be noticed that, for both cephalometric measurements and for the three groups, the measurements obtained on the second radiographs were larger than those of the first radiographs, which indicates the occurrence of growth. Additionally, this increment was not linear and was different among groups, both for S-N and Co-Gn measurements, which demonstrates that growth was influenced by the maturation stage of the patient.

Table 2 presents the result of ANOVA and Tukey's test for growth increments in S-N and Co-Gn measurements in Groups I, II and III. It can be noticed that there was difference in the mean increment values among the three groups, with larger growth for Group III, followed by Group I and smaller in Group II, both for S-N and Co-Gn cephalometric measurements. However, for S-N measurement, the growth difference among the groups was not statistically significant $(\mathrm{p}=0.56)$, whereas for Co-Gn the mean growth increment in Group III was significantly larger $(p=0.001)$ compared to Groups I and II.

\section{DISCUSSION}

Orthodontic treatments involving skeletal changes require information on the growth potential, i.e., the orthodontist must be aware of whether it is happening and which percentage of growth should be expected. The present study investigated whether the maturation stages, as determined by the evaluation of cervical vertebrae, might be related to the cranial and mandibular growth at the initial periods of PGS, considering that the craniofacial complex may be influenced by intrinsic and extrinsic factors that determine each patient's growth rate, as well as the general development. Thus, assessing the chronological age might not be the better way to perform this analysis.

The VMI was used to estimate the PGS period because it has been shown ${ }^{8,9,11,12}$ that the cervical vertebrae are easily observed on lateral cephalometric radiographs, which routine imaging exams in the orthodontic practice. This would reduce patients' exposure to radiation. Moreover, studies have reported positive correlations between VMI and the carpal index of $89 \%, 94 \%{ }^{8}$ and $74 \%{ }^{11}$, which demonstrates its validity.

The decision to evaluate the growth of the cranial base (S-N) and total mandibular length (Co-Gn) was based on the literature, since Lewis, et al. ${ }^{13}$ (1985) mentioned that the PGS is common in these two structures. Moreover, VelliniFerreira $^{22}$ (2001) mentioned that the cranial base and mandible present similar growth because they present the same type of ossification, namely chondral ossification.

TABLE 2- Application of ANOVA and Tukey's test to the increments in S-N and Co-Gn cephalometric measurements in Groups I, II and III

\begin{tabular}{lll}
\hline & \multicolumn{2}{c}{ Growth increment $(\mathrm{mm})$} \\
Groups & S-N & Co-Gn \\
\hline I & $1.39^{\mathrm{A}}$ & $3.22^{\mathrm{A}}$ \\
II & $1.18^{\mathrm{A}}$ & $2.89^{\mathrm{A}}$ \\
III & $1.83^{\mathrm{A}}$ & $6.14^{\mathrm{B}}$ \\
\hline
\end{tabular}

Means followed by different letters in the same column are different from each other according to the Tukey's test, at a significance level of $5 \%$.

TABLE 1- Descriptive statistics of S-N and Co-Gn cephalometric measurements on the first and second radiographs in Groups I, II and III

\begin{tabular}{|c|c|c|c|c|c|c|c|c|c|c|c|}
\hline \multicolumn{12}{|c|}{ Measurements $(\mathrm{mm})$} \\
\hline \multicolumn{6}{|c|}{ S-N } & \multicolumn{6}{|c|}{ Co-Gn } \\
\hline \multicolumn{2}{|c|}{$\begin{array}{l}\text { Group I } \\
(n=22)\end{array}$} & \multicolumn{2}{|c|}{$\begin{array}{l}\text { Group II } \\
(n=14)\end{array}$} & \multicolumn{2}{|c|}{$\begin{array}{l}\text { Group III } \\
(n=9)\end{array}$} & \multicolumn{2}{|c|}{$\begin{array}{l}\text { Group I } \\
(n=22)\end{array}$} & \multicolumn{2}{|c|}{$\begin{array}{l}\text { Group II } \\
(n=14)\end{array}$} & \multicolumn{2}{|c|}{$\begin{array}{c}\text { Group III } \\
(n=9)\end{array}$} \\
\hline d I & Rd II & Rd I & Rd II & $\mathrm{Rd} I$ & Rd II & Rd I & Rd II & Rd I & Rd II & Rd I & $\mathrm{Rd} \|$ \\
\hline 6.9 & 68.3 & 66.5 & 67.7 & 69.0 & 70.8 & 103.3 & 106.5 & 104.8 & 107.7 & 102.3 & 108.4 \\
\hline 3.1 & 3.3 & 2.9 & 3.4 & 2.0 & 2.8 & 4.6 & 4.8 & 5.8 & 6.3 & 5.2 & 5.9 \\
\hline 5.5 & 66.8 & 64.2 & 65.0 & 65.6 & 66.2 & 101.2 & 104.3 & 100.3 & 102.8 & 93.9 & 99.0 \\
\hline 8.3 & 69.8 & 68.7 & 70.3 & 72.3 & 75.4 & 105.3 & 108.9 & 109.3 & 112.6 & 110.7 & 117.9 \\
\hline
\end{tabular}

$\mathrm{SD}$ = standard deviation; $\mathrm{Mn} \mathrm{M}=$ minimum measurement; $\mathrm{Mx} \mathrm{M}$ = maximum measurement. 
As presented in Table 1, S-N and Co-Gn cephalometric measurements showed growth during the study period, i.e. during the pubertal growth spurt. This result demonstrates that the maturation stages of the cervical vertebrae were valid for the evaluation of cranial and mandibular growth, corroborating the findings of previous studies ${ }^{2-4,6,14,16}$. Additionally, Prates, et al. ${ }^{18}$ (1982) reported that the bone maturation method would be the most adequate to evaluate the period of occurrence and magnitude of craniofacial growth because both are affected by the same process, especially with regard to the changes in mandibular dimensions.

However, despite the occurrence of growth, this was not statistically significant for S-N, i.e., neither marked growth nor peak of development was observed for this measurement. Similarly, Hunter ${ }^{10}$ (1966) and Moore, et al. ${ }^{15}$ (1990) reported that the S-N measurement did not demonstrate a significant increase in growth during PGS when compared to other cephalometric measurements. These authors ${ }^{10,15}$ mentioned that S-N cephalometric measurement does not conclusively present growth acceleration, suggesting the occurrence of PGS. On the other hand, Prates, et al. ${ }^{18}$ (1982) and Arat, et al. ${ }^{1}$ (2003) attempted to demystify the information that $\mathrm{S}-\mathrm{N}$ is a stable cephalometric measurement because it presents growth during puberty. Arat, et al. ${ }^{1}$ (2003) reported that S-N measurement is not stable because the activity of the spheno-occipital synchondrosis is continued up to growth completion, which would affect the stability of the anterior cranial base.

On the other hand, growth was more expressive for Co$\mathrm{Gn}$, with the detection of a statistically significant peak of development for Group III, in which the patients were in the transition (3) stage in both cephalometric radiographs (with a 12-month interval). This represents the maximum speed of PGS according to the VMI-based evaluation. The growth process was investigated by Baccetti, et al. ${ }^{2}$ (2002), who reported that the peak speed of mandibular growth, as evaluated by the VMI, occurred from the acceleration (2) stage to the transition (3) stage. However, Baccetti, et al. ${ }^{2}$ (2002) proposed another method for interpretation of the maturation events of the cervical vertebrae $(\mathrm{C} 2, \mathrm{C} 3$ and $\mathrm{C} 4)$ relative to the mandibular growth and did not employ the method described by Hassel and Farman ${ }^{9}$ (1995), which, in turn, limits the comparisons between studies.

The present study revealed larger growth at the transition period of VMI (Group III), followed by the initiation or acceleration period (Group I), and smaller growth between the initiation and acceleration periods or between the acceleration and transition periods (Group II). This demonstrates that growth was not linear for the studied population. This results differ from those of Prata, et al. ${ }^{17}$ (2001), who stated that maxillary and mandibular growth at the acceleration period of PGS tends to be linear, and affirmed that there is no difference in growth increments during the acceleration and peak stages of the PGS as demonstrated by cephalometric measurements. Differences between the present results and the study of Prata, et al. ${ }^{17}$ (2001) may be assigned to the fact that the latter evaluated the PGS by means of the CMI, rather than the VMI as in our study.

The findings of the present investigation art consistent with the conclusion of Prates, et al. ${ }^{18}$ (1982) that the evaluation of facial growth requires more than angular and linear measurements. Thus, cephalometric analyses are more significant when correlated with other physiological changes occurring in children. This should emphasize the need that the orthodontist considers the child not as a skullface unit, but rather as an integrated organism. Finally, additional studies on this issue, evaluating other cephalometric measurements, should be conducted.

\section{CONCLUSIONS}

In conclusion, the maturation stages of VMI were valid for estimation of cranial and mandibular growth at the initial stages of PGS, since both measurements increased within the study period, thus rejecting the null hypothesis. However, the method demonstrated to be more applicable when used for estimation of mandibular development, as a significant growth peak for Co-Gn coinciding with VMI peak was observed.

\section{ACKNOWLEDGEMENT}

To Professor MSc Djalma Roque Woitchunas, who allowed utilization of the files of the discipline of Orthodontics; and to Professor MSc Adriano Pasqualotti, who performed the statistical analysis of the present study.

\section{REFERENCES}

1- Arat ZM, Rübendüz M, Akgül AA. The displacement of craniofacial reference landmarks during puberty: a comparison of three superimposition methods. Angle Orthod. 2003;73(4):374-80.

2- Baccetti T, Franchi L, McNamara JA Junior. An improved version of the cervical maturation (CVM) method for the assessment of mandibular growth. Angle Orthod. 2002;73(4):316-23.

3- Chen F, Terada K, Hanada K. A new method of predicting mandibular length increment on the basis of cervical vertebrae. Angle Orthod. 2004;74(5):630-4

4- Chen F, Terada K, Hanada K. A special method of predicting mandibular growth potential for class III malocclusion. Angle Orthod. $2005 ; 75(2): 187-91$.

5- Chen SK, Chen YJ, Yao CCJ, Chang HF. Enhance speed and precision of measurements in a computer-assisted digital cephalometric analysis system. Angle Orthod. 2004;74(4):501-7.

6- Franchi L, Baccetti T, McNamara JA Junior. Mandibular growth as related to cervical vertebrae maturation and body height. Am J Orthod Dentofacial Orthop. 2000;188(3):335-40.

7- Flores-Mir C, Burgess CA, Champney M, Jensen RJ, Pitcher MR, Major PW. Correlation of skeletal maturation stages determined by cervical vertebrae an hand-wrist evaluations. Angle Orthod. 2006;76(1):1-5. 
8- García-Fernandes P, Torre H, Flores L, Rea J. The cervical vertebrae as maturational indicators. J Clin Orthod. 1998;32(4):221-5.

9- Hassel B, Farman AG. Skeletal maturation evaluation using cervical vertebrae. Am J Orthod Dentofacial Orthop. 1995;107(1):58-66.

10- Hunter CJ. The correlation of facial growth with body height and skeletal maturation at adolescence. Angle Orthod. 1966;36(1):4454

11- Kucukkeles N, Acar A, Biren S, Arun T. Comparison between cervical vertebrae and hand-wrist maturation for the assessment of skeletal maturity. J Clin Pediatr Dent. 1999;24(1):47-52.

12- Lamparski DG. Skeletal age assessment utilizing cervical vertebrae [masters thesis]. Pittisburg: Universty Pittisburg; 1972.

13- Lewis AB, Roche AF, Wagner B. Puberal spurts in cranial base and mandible: comparisons within individuals. Angle Orthod. $1985 ; 55(1): 17-30$.

14- Mito T, Sato K, Mitani H. Predicting mandibular growth potentia with cervical vertebral bone age. Am J Orthod Dentofacial Orthop. $2003 ; 124(2): 173-7$

15- Moore RN, Moyer BA, DuBois LM. Skeletal maturation and craniofacial growth. Am J Orthod Dentofacial Orthop. 1990;98(1):3340

16- O’Reilly MT, Yanniello GJ. Mandibular growth changes and maturation of cervical vertebrae. Angle Orthod. 1988;58(2):17988 .

17- Prata THC, Medici E Filho, Moraes LC, Moraes MEL. Estudo do crescimento maxilar e mandibular na fase de aceleração do surto de crescimento puberal. Rev Dent Press Ortodon Ortopedi Facial. $2001 ; 6(4): 19-31$

18- Prates NS, Consani S, Vieira S. Crescimento crânio-facial e maturação óssea. Rev Gauch Odontol. 1982;30(4):261-8.

19- Sato K, Mito T, Mitani H. An accurate method of predicting mandibular growth potential based on bone maturity. Am J Orthod Dentofacial Orthop. 2001;120(3):286-93.

20- Silveira AM, Fishman LS, Subtelny JD, Kassebaum DK. Facial growth during adolescence in early, average and late maturers. Angle Orthod. 1992;62(3):185-90.

21- Thompson GW, Popovich F. Relationship of craniofacial changes and skeletal age increments in females. Hum Biol. 1973:45(4):595603

22- Vellini-Ferreira F. Crescimento e desenvolvimento craniofacial. In: Vellini-Ferreira F. Ortodontia: diagnóstico e planejamento clínico. São Paulo: Artes Médicas Ltda; 2001. p. 32-55. 